\title{
Skeletal Tuberculosis- Review of Literature and Few case reports
}

\author{
Dr.Chittiboyina Sumalata,' Dr. B.Arundhathi ${ }^{2}$ \\ 'State TB Training and Demonstration Center, India \\ ${ }^{2}$ Medical Officer, Nalgonda, Telangana, India
}

\begin{abstract}
Correspondence: Dr. Chittiboyina Sumalata, State TB Training and Demonstration Center, Irramnuma, Hyderabad, Telangana state, India, Email: drsumachittiboyina@gmail.com; Dr. B.Arundhathi, Medical Officer, Nalgonda, Telangana, India.
\end{abstract}

Received: November 13, 2018 | Published: November 29, 2018

Copyright@ 2018 Sumalata et al. This is an open access article distributed under the terms of the Creative Commons Attribution License, which permits unrestricted use, distribution, and reproduction in any medium, provided the original author and source are credited.

\begin{abstract}
Extrapulmonary tuberculosis forms $15 \%$ of total tuberculosis in India. Skeletal tuberculosis which constitutes bone and joint tuberculosis, results from haematogenous spread from a pulmonary or other visceral or lymph node focus. Tuberculosis osteomyelitis was described by Nelatoo (1837); histologic morphology was given by Rokitansky (1884); tuberculosis nodule in a joint was seen by Koster (1869); and synovial tuberculosis by Volkmann (1879).
\end{abstract}

Case No. 1: A case of Shoulder joint Tuberculosis which was relatively rare, was diagnosed in a middle aged farmer after taking proper history of pain and inability to move. He was investigated appropriately with radiological images and the case eventually responded to the anti-tuberculosis treatment.

Case No. 2: A case of rib osteomyelitis was diagnosed when the young lady had only a complaint of pain in lower chest right side. The diagnosis of TB was reached after she had empyema and the same pus was tested for TB DNA. The decrease in pain and relieve of symptoms noticed after the initiation of

\section{Introduction}

Tuberculosis caused by Mycobacterium tuberculosis is one of the dreadful diseases affecting almost all parts of the body, that affecting lungs and its parenchyma is termed as pulmonary tuberculosis, when affecting parts other than lungs it is extrapulmonary tuberculosis. Pulmonary tuberculosis is more infectious and is easier to diagnose based on symptoms when compared to extrapulmonary tuberculosis.

Most of the times in extrapulmonary tuberculosis, demonstration of microbiological evidence is often not possible, that is where the diagnosis depends on high clinical suspicion and supportive other investigations like radiological, haematological and biochemical tests.

Skeletal Tuberculosis, involving bones and joints, is one form of extrapulmonary tuberculosis, accounting for 10-35 \% of extrapulmonary tuberculosis and $2 \%$ of all forms of TB.

Tuberculosis is an ancient disease, features of spinal tuberculosis was identified in Egyptian mummies, ${ }^{1,2}$ and analysis of 483 pre-Columbian skeletons in Chile showed lesions consistent with bony tuberculosis in 2 percent of cases. ${ }^{3}$ Subsequently, molecular studies have established the presence of Mycobacterium tuberculosis complex DNA in ancient bony specimens. ${ }^{2,4}$

Tuberculosis can cause characteristic skeletal changes, such as collapse of the vertebrae (Pott's disease), periosteal reactive lesions, and treatment with Anti tuberculous treatment. She had surgical intervention for the same.

Case No. 3 A young lady complained of pain and swelling in left wrist for a long duration. MRI showed bone marrow oedema in distal row of carpal bones with loss of articular cartilage and small erosion noted in trapezoid, base of metacarpal and capitates and base of third metacarpal joint. The diagnosis of tuberculosis was supported with Immunoglobulin Releasing Assay (IGRA) which was positive. Anti tuberculous drugs were given, and she responded well.

Case No. 4 A middle aged man who was suffering from low back ache from 3 years had been diagnosed as Potts spine at L5 -S1 with the help of MRI spine. He was started with Anti tuberculosis drugs and he responded well.

All the cases were also worked up for primary pulmonary involvement.

Keywords: skeletal tuberculosis, extrapulmonary, anti tuberculous treatment

osteomyelitis. ${ }^{5}$ Such paleopathological changes have been reported in pre-dynastic (3500-2650 BC) Egypt, ${ }^{6}$ and Neolithic (3200-2300 BC) Sweden culturally associated with the earliest cattle breeders. ${ }^{7}$ These are the oldest cases of human tuberculosis confirmed by ancient DNA. Older cases recognized by skeletal changes alone were found in Neolithic Italy at the beginning of the fourth millennium BC. ${ }^{8,9}$

The proportion of skeletal TB among HIV-infected individuals is comparable with the proportion of skeletal TB among HIV-uninfected individuals.

The most common cause of mycobacterial osteomyelitis and arthritis in world is Mycobacterium tuberculosis. ${ }^{10}$

Of all forms of skeletal TB, Pott's spine is commonest form.

\section{Case Reports}

Case No. 1 A case of shoulder joint tuberculosis which was relatively rare, was diagnosed in a middle aged farmer after taking proper history of pain and inability to move. The involvement of shoulder joint accounts for $0.9-1.7 \%$ of total skeletal tuberculosis. ${ }^{11}$ The diagnosis was based on clinical and radiological findings. The head of the humerus is probably a prime target location as destructive changes are maximally seen in it. The findings seen in our case were in head of humerus. He was investigated appropriately with radiological images and the diagnosis of shoulder TB was established. The patient was 
offered anti-tuberculous treatment in DOTS under Revised National Tuberculosis Control Program. He was also supported with ancillary drugs like Paracetamol and pain killers. In due course of time, the pain subsided and he improved symptomatically. No plaster of Paris or spica was used. His movements regained in due course of treatment. The duration of treatment was 12 months.

Case No. 2 A case of rib osteomyelitis was diagnosed when the young lady had only a complaint of pain in lower chest right side. The diagnosis of TB was reached after she had empyema and the same pus was tested for TB DNA. Empyema thoracis was drained and rib involvement was noticed. The affected rib was removed, and she was advised on anti-tuberculous treatment. She approached public sector for TB treatment under DOTS (Directly Observed Treatment Shortcourse Chemotherapy). The decrease in pain and relieve of symptoms noticed after the initiation of treatment with anti-tuberculous treatment. She was given anti-tuberculosis treatment for 15 months.

Case No. 3 A young lady of 28 years complained of pain and swelling in left wrist for a long duration as much as 3 months (Figure 1). She had been using various treatment modalities prescribed by various physicians. When nothing was pinpointing the diagnosis, MRI of wrist was planned where it showed bone marrow oedema in distal row of carpal bones with loss of articular cartilage and small erosion noted in trapezoid, base of metacarpal and capitates and base of third metacarpal joint. Mild soft tissue oedema was also noted on dorsum of wrist. Anti-tuberculosis drugs for 14 months were given and she responded well. Non-steroidal anti-inflammatory drugs were given whenever she was complaining of pain.

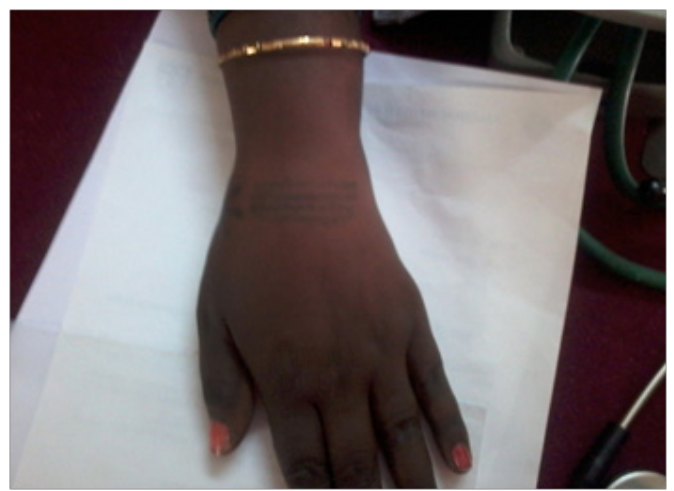

Figure I Swelling on left wrist.

Case No. 4 In another case where a middle aged man who was suffering from low-back ache for three years. He was taking different types of treatment for his low-back ache. When MRI was advised, the following findings were noticed (Figure 2):

1. Pre- and paravertebral exudates noticed at the level of L5 \& S1;

2. Features were suggestive of Infective spondylitis.

He was started with anti-tuberculosis drugs and duration of treatment was 15 months and he responded well.

The above cases of skeletal tuberculosis, the diagnosis was made by clinic-radiological evidences. In only one case (Case No. 2), there was microbiological evidence which was done by TB DNA for the pus that was obtained from the thorax, which showed positive for Mycobacterium tuberculosis.

Tuberculous osteomyelitis and arthritis generally arise from reactivation of bacilli lodged in bone during the original mycobacteremia of primary infection. The predilection of the bacillus for the spine and large joints can be explained by the rich vascular supply of the vertebra and growth plates of the long bones. Tuberculous arthritis is believed to result from extension of an initial infectious focus in the bone to the joint. Infrequently, tuberculous bacilli travel from the lung to the spine along the Batson paravertebral venous plexus or by lymphatic drainage to the paraaortic lymph nodes. ${ }^{1}$

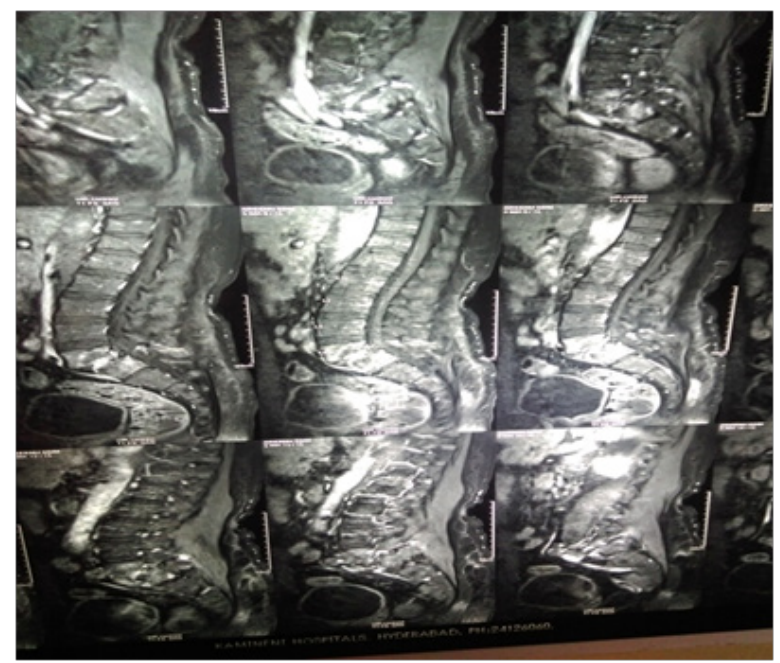

Figure 2 Radiological images showing involvement of spine

TB is one of the most common causes of rib osteomyelitis. Symptoms like pain and swelling are observed.

In all the above cases, there was pulmonary involvement along with extrapulmonary in case 2 where there was rib involvement.

The chemotherapy was advised and given after expert consultation and there were no relapses after completion of treatment.

It is always challenging to diagnose a case of extrapulmonary TB because obtaining sample is difficult especially in skeletal TB. The diagnosis mostly made on clinical acumen and radiological evidences.

In spinal $\mathrm{TB}$ with no neurological deficit, conservative treatment with a combination of antituberculous drugs yields similar long-term results, with no late relapse or late-onset paraplegia, when compared to surgery with anterior debridement and fusion or anterior debridement alone. ${ }^{12}$ Back pain is most common complaint in Potts spine.

However, when there is a diagnosis of skeletal tuberculosis, the recommendation of anti-tuberculous drugs is longer when compared to that given for pulmonary TB. Operative interventions were not required in all cases, but there was surgical intervention done prior to diagnosis of TB was made in case No. 2 TB rib osteomyelitis. Surgical management is required when there is no improvement with adequate chemotherapy. Surgery may also be done if the therapeutic outcome is not satisfactory or an unacceptable deformity is left after the treatment. A loss of motion so severe that it hampers the activity of daily living is also an indication for surgery, if feasible.

\section{References}

1. Bloom BR. Tuberculosis: Pathogenesis, Protection, and Control. ASM press; 1994.

2. Hershkovitz I, Donoghue HD, Minnikin DE, et al. Detection and molecular characterization of 9000-year-old Mycobacterium tuberculosis from a Neolithic settlement in the Eastern Mediterranean. PloS One. 2008;3(10):e3426.
Submit your Article | www.ologypress.com/submit-article

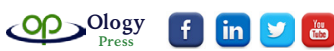


3. Arriaza BT, Salo W, Aufderheide AC, Holcomb TA. Pre-Columbian tuberculosis in northern Chile: molecular and skeletal evidence. Am J Phys Anthropol. 1995;98(1):37-45.

4. Donoghue HD, Lee OY-C, Minnikin DE, Besra GS, Taylor JH, Spigelman M. Tuberculosis in Dr Granville's mummy: a molecular re-examination of the earliest known Egyptian mummy to be scientifically examined and given a medical diagnosis. Proc R Soc Lond B Biol Sci. September 2009:rspb20091484. doi:10.1098/rspb.2009.1484

5. Ortner DJ. Identification of Pathological Conditions in Human Skeletal Remains. Academic Press; 2003.

6. ZINK A, HAAS CJ, REISCHL U, SZEIMIES U, NERLICH AG. Molecular analysis of skeletal tuberculosis in an ancient Egyptian population. J Med Microbiol. 2001;50(4):355-366. doi:10.1099/00221317-50-4-355

7. Nuorala E, Götherström A, Ahlström T, Donoghue HD, Spigelman M, Lidén K. MTB complex DNA in a Scandinavian Neolithic passage grave. 2004. http://urn.kb.se/resolve?urn=urn:nbn:se:su:diva-23297. Accessed November 28, 2018.
8. Formicola V, Milanesi Q, Scarsini C. Evidence of spinal tuberculosis at the beginning of the fourth millennium BC from Arene Candide cave (Liguria, Italy). Am J Phys Anthropol. 1987;72(1):1-6. doi:10.1002/ ajpa. 1330720102

9. Canci A, Minozzi S, Tarli SMB. New Evidence of Tuberculous Spondylitis from Neolithic Liguria (Italy). Int J Osteoarchaeol. 1996;6(5):497501. doi:10.1002/(SICI)1099-1212(199612)6:5<497::AIDOA291>3.0.CO;2-O

10. Good RC, Snider DE. Isolation of Nontuberculous Mycobacteria in the United States, 1980. J Infect Dis. 1982;146(6):829-833.

11. Gardam M, Lim S. Mycobacterial osteomyelitis and arthritis. Infect Dis Clin North Am. 2005;19(4):819-830. doi:10.1016/j.idc.2005.07.008

12. Jain AK. Tuberculosis of the spine: a fresh look at an old disease. J Bone Joint Surg Br. 2010;92(7):905-913. doi:10.1302/0301-620X.92B7.24668 